\title{
A Study on the Selection Principle of Industrial Clusters based on Industrial Integrated Design Case Study of Forestry
}

\author{
Xinxi Jiang ${ }^{1}$, Wei Zhang ${ }^{2}$, Minwen $\mathrm{He}^{3}$ \\ ${ }^{1}$ Professor of Business School, Jiangxi Normal University, 330022 Nanchang Jiangxi, China \\ ${ }^{2}$ Postgraduate of School of intercultural studies, Jiangxi Normal University,Nanchang, 330022, \\ China \\ ${ }^{3}$ Postgraduate of Business School, Jiangxi Normal University, Nanchang, 330022, China
}

\begin{abstract}
Technical cluster which consists of core technology and relevant matching technology can support or induce a core industry. By integrating the basic conditions and professional integration, it can be pushed up to an integrated industrial cluster, matched to the core industry. Thus a strategic core industry can support or induce an industrial cluster which has organic links. Only if we follow the principles when selecting industrial clusters can the benefits be maximized. In this paper, I take forestry as an example, analysing the application of selection principle on integrating forest resources, as well as its advantages.
\end{abstract}

Keywords. industrial clusters; industrial integrated design; selection principle

\section{Introduction}

The reason why the core industry which has strategic significance can support or induce an industrial cluster is that the core industry can not survive alone for long. Population of the core industries needs good living services, security services, and education services, which induce services industry for labor, security education and training industry, and services industry for community; raw materials supply need specialized suppliers, and products need circulation, which generate industries of raw materials and products supply and marketing; the products of core industry need packaging and industrial product design, advertising and media, which derived from packaging design and advertising industry of the core industries; technology and raw materials supply, the supply of key components, management consulting system, financial services, transportation services, communication services, and other basic conditions that the core industry bases on can evolve into a relatively complete industry cluster matches with the core industry through the special integration.

\section{Selection principle Studies}

\subsection{The principle of forward integration}


Industrial cluster is a dynamic cycle collection, and the logistics, business flow, and information flow are the three dynamic main bodies. These flow main bodies can be divided into front and rear flow according to flow direction. The so-called front flows refer to the industries located in downstream direction (forward direction) of core industry. These industries generally more close to the market, or close to the field of consumption. The realization of the value-added is more indeed than the core industries itself. Therefore, forward integration help the core industries to establish mechanisms for resisting risks in higher level, lower transaction costs between industries, and improve the competitiveness of core industries.

For example, as the integration of core industry and furniture manufacturing, furniture design and furniture retail business, wood lumber industry is forward integration. Another example is the wood pulp industry. It belongs to core industry. Many subsequent industries can be taken in this clusters, such as packaging industry, the utilization of waste paper industry (density fiberboard in waste paper manufacture, etc.), activated carbon manufacturing industry, and the use of textile industry, and forms an industrial cluster. The more closely the core industries integrate forward, the greater the economic rate of return (more reasonable), because the ultimate front line of industrial cluster is the ultimate product market--business services industries, which ultimately realize value-added of industries and possess the largest profits. From the point of economic sense, forward integration actually is an integration of industrial structure in the direction of first market.

\subsection{The principle of behind integration}

As mentioned above, the so-called behind integration refers to the industries which lie in the updriftside (background level) of core industry. These industries generally are more close to natural resources, or adjacent to non-integrated operating resources (human, material and financial resources, time, space, etc.).These industries have low value-added, or more difficulty in achieving added value. But developing behind (background) industries can bring more eco-efficiency. Economic benefits of core industry can be directly transferred from front industry to behind industry through behind integration, which maintains the growth of eco-efficiency, so ecological and economic benefits of industrial cluster can be coordinated and the social benefits will also be improved.

For example, as a behind (rear) integration of the core industry, furniture manufacturing industry could integrate wood manufacturing industry, timber cultivation industry, seed cultivation industry, forestry by-product utilization industry and other industries. They can form an industrial cluster. It not only can stabilize the cost of raw materials, but also can protect forest ecosystems and improve eco-efficiency. From the academic point of view, the rear integration is the equivalent of integration of industrial structure in the direction of the secondary market in industrial economics.

\subsection{The principle of strategic assembly}

Proceed from the economic principle of the comparative advantage, we can discover that it is an effective method to carry out strategic assembly for industries.such as grow out of nothing, from small to large, from the humble to the well-established, obeying the comparative advantages.

Chitin new materials industrial cluster can be achieved by taking the strategic assembly. First of all determine the raw materials industries (traditionally we not only use aquaculture shrimp and crab shells as raw materials to produce chitin, but also adopt the way of raising crayfish in rice paddy and culturing flesh fly broadly. Chitin industrial model in China is different from in Europe, America, Japan and South Korea), and then develop intermediate manufacturing industries (to produce highly competitive chitosan, chito-oligosaccharide, peptide protein, edible gelatin and other medicine, food and industrial intermediates with high bio-technology), to increase output of front industries (carry out effective forward integration and establish a complete industrial cluster), 
which can make chitin new material to be China's strategic reserve resources, and China will have the world's largest comparative advantage.

Another example is plain forestry or urban forestry. They could adopt strategic assembly to achieve maximum benefits of plain forestry industries or maximum benefits of urban forestry industries. Plain forestry — areas of fast-growing protection forest. The culture of wormwood, basil, mint and other herbs in the forest (used as raw materials for foods and medicines) meets the demand for short-term gains. The manufacturing of single-board packing materials and the establishment of plain characteristic forest tourism industry could make plain to reach a good condition. Urban forestry — areas of economic forest and park-trees combine with suburban coppice (such as Cinnamomum dwarf trees and fruit trees) operations, and establish tourist farm forestry and forest operations area (hand-made, happy lin, forest Animal adoption) to enhance comprehensive benefits of industrial cluster. The principle of strategic assembly has three planning ways: basic modular approach, DIY modular approach, features modular approach. Basic modular approach_orients core industry as the basic module. It is the essential basis to choose the basis of cluster; DIY modular approach—selects industrial cluster basing on existing industry in economic planning area and determines the content of the industrial structure; features modular approach - it is a selection way that characteristic industries in economic planning area should be chosen carefully as characteristic structural industries. Such as "the three forestry systems (forestry industry system, forestry ecological system, and ecological and cultural system) building" can be described by "the three forestry industrial clusters": that is, industrial cluster of forestry resources, forestry eco-industrial cluster, industrial cluster of ecology and culture. Resource industry is the basic module, eco-industry is the DIY module, and ecological and cultural industry is a characteristic module.

\subsection{The principle of regional integration}

Integrate industrial clusters of a region into a big cluster in accordance with the technology roadmap, market rationality, regional characteristics, that is, the principle of regional integration.

For example, the ceramic industry in Jiangxi Province is a big industrial cluster. In this cluster, there are Jingdezhen ceramic industrial cluster and Jizhou ancient kiln ceramic industrial cluster, and forestry is an industrial cluster associated with the ceramic industrial cluster. From the comparative advantages of Jiangxi Ceramics, if Jiangxi Ceramic integrates industrial cluster of Jizhou ancient kiln ceramic, Jiangxi forestry industries will be required to provide a large number of branches of mason pine to be fuel. However, from resources innovation of forestry point of view, wetlands pine trees will be cultivated to meet this need. If Jizhou ancient kiln ceramic also take innovation on packaging materials (for example, using wood packaging material can greatly enhance the value-added), slash pine wood will be an ideal choice. Forestry industrial cluster can increase the industry of forest cultivation and the industry of timber wood processing, and it can become a powerful complementary industrial cluster with ceramics industries in Jiangxi Province.

\subsection{The principle of dynamic equilibrium}

Due to the existence of non-uniformity between business resource elements within the industry, thereby enabling factor uneven development within the industry; due to the disproportions in development environment and development process in inter-cluster within the industry, leading to the differences and imbalance of the development speed and scale within inter-industry. In dealing with such a dynamic problem of uneven development, it's very important to find correction method of homeostasis. The following correction method can be used as the principle of homeostasis reference: multi-path selection method (pre-select multiple parallel paths, when an industry is in an unbalanced position, use another industry with parallel progress as a replacement); technical amendment method (by making technical amendments to adjust the imbalanced relations within the industry or inter-industry so that the industry cluster elements reach a new equilibrium); 
marketing amendment method (via changes in the marketing mix to adjust the imbalance fluctuations from within-cluster); scale adjustment method (by adjusting the scale of the overall development of industrial clusters to control elements of unbalanced development or industrial development within the cluster) and so on. Homeostasis amendment method as a basic means of regulating the sustainable development of industrial clusters, its use is limited, excessive use can lead to greater inter-industry imbalance within the cluster. But from a philosophical point of view, between the cluster and the cluster, between clusters within the industry, among the various elements within the industry, the movement is absolute, standstill is relative-that is always in a state between the imbalance and balance, and to a large extent, Human beings are lack of correct understanding in the natural or imbalance of the industry rules (or lack a comprehensive understanding in the stage of development of human knowledge), so only when the scientific and technical knowledge to fully achieve a rational understanding of natural and industrial law, it's possible to adjust or control the imbalance or maintain the relative balance by using the right way.

Exploration and innovation is an important step in understanding natural law and industrial imbalance law, but the results of exploration and innovation are anxiously used to ask for the nature and the adjustment of industrial operations, the choice of risk and opportunity is still in half.

Take Bio-engineering as example, biotechnology can lead to different core technologies, thereby inducing various core industries and industry clusters-biomedicine, modern agriculture, modern brewing industry, biochemical engineering and other modern industries, but the modern brewing industry (for example, by using engineering bacteria vitamins, beta carotene, industrial ethanol and other industries were achieved) may lead to the conflict with modern agriculture (such as organic cultivation, fine grain varieties), with that of modern agriculture market deprived (or limit), the agricultural population reduction in the level of income resulting from agro-ecological imbalance, that is, modern agriculture markets are deprived (or limited), the level of income of the agricultural population decline which leads to agro-ecological imbalance. With the development of biomedical and biochemical engineering industry cluster, the imbalances between traditional Chinese medicine, traditional chemical engineering industry cluster were induced, the results may bring out a recession in the pharmaceutical market, or traditional chemical engineering industry shock. Therefore, the highest purpose of dynamic equilibrium in selecting industrial cluster, is find a balancing way to push the industry forward gradually, steadily and make use of it among the rapid development of science and technology and social innovation movement.

\subsection{The principle of knowledge-culture integrated}

Classify according to the structural features of knowledge culture structure in industry population,so that the industry cluster has the best selection methods of knowledge culture integration. The whole knowledge culture of human beings is a collection of development along time, regional space, human stratum multiple dimensions, and the development of human knowledge culture determinate the development of human industry, therefore human knowledge culture subdivision also decides the industrial differentiation (subdivision). The knowledge culture competence of industrial population individuals is very limited, even a good scientist or entrepreneur also has limitations in knowledge culture and technical capacity, so the "integration" -the equivalent of precision which achieved to organic integration of contact-is the tips of industrial operations.

Human cultural differences can lead to the differentiation of education, knowledge and ability structure, and even behaviors, lifestyles, and values.In this sense, even the same type of industry, in the context of a different structure of human culture, the way they operate is also different. That is also called "modern industry", the cultural connotation of modern knowledge they contained is different as well. The principle of knowledge-culture integrated can be subdivided into the following four parts: ethnic integration, regional specialties integration, industrial features integration, historic features integration. 


\subsection{The principle of diversification-admitted}

As mentioned above, because of the dynamic uncertainty in industrial development operations, which risks the stabilized and continued development of industrial clusters, so in order to locate and resolve the risk due to the imbalances, it's necessary to set a backup mechanism from the multiple angle in correcting the imbalances--that is the disruptive selection for that advance to allow industry clusters combined.

For example, in the colonization process, fiberboard industry can be preset number of options: combined with other wood-based panels (particleboard, plywood) industry-technology and equipment integration; and combined with pulp industries-fiber materials (wood, herbal paste , paper, etc.) integration; and combined with furniture and building materials industries-forward market integration; combined with natural mineral mining industries-technical features (mica board, asbestos, clay plates, etc.) integration; combined with nano materials industry-functional Materials innovation areas integration .

\section{Conclusion}

In order to obtain a new and complementary technologies, gain benefit with the technologies and knowledge, accelerate the learning process, reduce transaction costs, or build overcome market barriers and achieve economies of collaboration, innovation and risk dispersion, therefore industry is made. Industry groups is an effective way of space competition, you need to choose on the basis of certain principles when doing industrial groups construction. Only by having good understanding of the characteristics and advantages of industrial clusters and following the right selection principle can a reasonable industrial layout be formed. In addition, it can increase competitive advantage.

\section{References}

1. Harrison, Bennett. Are industrial clusters losing their cluster? Technology Review [J]. 1994, 97(4).

2. Jacobs, D., De Man, A. P., Clusters, Industrial Policy and Firm Strategy: A Menu Approach [J]. Technology Analysis \& Strategic Management, 1996- 04.

3. Deng Heping, Jiang Xin-xi. Geological New Material [M]. Hunan Science Press, 2006(206208).

4. Wang Tianying. Research on the Problems of the Presumption and Viability Of Industrial Design and the Path of Choosing the Relevant Industries [J]. Economic Management, 2007(15). 